\section{Optical Crystallography}

\section{F. Donald Bloss}

(Mineralogical Society of America,

Washington, DC, 1999)

$x+239$ pages, $\$ 32.00$

ISBN 0-939950-49-9

Sitting down to lunch at the annual meeting of the Mineralogical Society of America in Ottawa, Canada, in about 1950, I was joined by two elderly gentlemen who introduced themselves, with a humorous twinkle in the eye, as the "Wright brothers." I remarked that I did not realize that the famous Wright brothers were interested in mineralogy. "Oh, we aren't Orville and Wilbur, but we've been involved in mineralogy for ages." Of course: the inventors of the Wright Polarizing Microscope, which was to become the subject of the present volume!

Beginning with a review of physical optics and the compound microscope, the polarizing microscope is introduced. The optical properties of isotropic substances is followed by notes on uniaxial and biaxial crystals. The (relatively new) spindle stage and its use with the computer program EXCALIBER (not included) for optical determinations are enthusiastically treated. The concluding chapter specifies the use of dispersion staining for the rapid identification of asbestos fibers. The arguments are well and abundantly illustrated; it seems a pity that the excellent color photographs of interference figures appear only on the back of the dust jacket. Review questions at the end of the chapters are designed to facilitate use of the book for teaching.

Reviewer: V.D. Frechette, now deceased, was Professor Emeritus of Alfred University and consulted for Oak Ridge National Laboratory, Lawrence Livermore National Laboratory, General Electric, Westinghouse, PPG Industries, and numerous other companies. He was a member of the Royal Swedish Academy of Arts and Sciences.

\section{A Guide to Monte Carlo Simulations in Statistical Physics David P. Landau and Kurt Binder (Cambridge University Press, Cambridge, 2000) \\ 398 pages, $\$ 100.00$ (hardcover), $\$ 37.95$ (paper) \\ ISBN: 0-521-65314-2 (hardcover), 0-521-65366-5 (paper)}

David Landau and Kurt Binder are among the leading practitioners in the application of Monte Carlo techniques, and they have applied these methods to a wide variety of problems in condensedmatter physics and statistical mechanics. They also are excellent writers who have contributed a very useful book for those interested in learning more about new developments in Monte Carlo methods and the range of applications.

Not long ago, a discussion of Monte Carlo methods in condensed-matter physics emphasized the Metropolis algorithm and single-spin and single-particle moves for systems at a fixed temperature. However, during the last decade there have been many new developments, both in the range of applications and in the developments of new techniques, that go way beyond the venerable Metropolis method. For example, Landau and Binder discuss cluster and multiple histogram methods, multicanonical sampling, configurational-biased Monte Carlo, quantum Monte Carlo and Monte Carlo renormalization group methods, as well as the treatment of long-range interactions and simulations of polymers in the context of complex liquids. As the title of the text indicates, the emphasis is on applications to complex systems, and although the authors discuss quantum systems such as the transverse Ising model and quantum crystals, the text does not discuss strongly correlated electron systems or density functional theory, two topics of much interest in materials science.

One of my pet peeves about much of the published literature involving computer simulations is that many details of the methods that are used are not discussed in sufficient detail to allow the nonexpert reader to evaluate or reproduce the results. Landau and Binder's text helps to fill this gap. For example, they discuss in detail how to analyze small systems, do finite size scaling, and estimate errors, and they provide much useful general advice. They also discuss the desirability of thinking small, testing the random-number generator, looking at systematic variations with system size and run length, and the necessity of calculatıng errors.

Landau and Binder's text is similar in scope to the recently published text Monte Carlo Simulations in Physics, by M.E.J. Newman and G.T. Barkema (Oxford University Press, 1999). Both texts are very well written and discuss most of the important new developments. The differences reflect the research interests of the authors and perhaps their generation. For example, Landau and Binder discuss the classical Heisenberg model in great depth, while Newman and Barkema discuss lattice-based ice models. Similarly, the latter authors give program listings in C, while Landau and Binder list their sample programs in Fortran 77. I would have preferred Fortran 90.

Both texts have more than enough useful tidbits and references to interest even experienced researchers in computer simu- lation. Given the relatively low cost of the paperback edition, I would highly recommend both texts to anyone doing simulations, including novice graduate students and experienced researchers, and readers who wish to obtain a better overview of the nature of Monte Carlo simulations.

Reviewer: Harvey Gould is a professor of physics at Clark University. He is co-author with Jan Tobochnik of an undergraduate-level text on computer simulations and, as of July 1 , is associate editor of the American Journal of Physics (with Jan Tobochnik as editor).

\section{Introduction to Texture Analysis: Macrotexture, Microtexture and Orientation Mapping}

Valerie Randle and Olaf Engler (Gordon \& Breach Science Publishers, Amsterdam, 2000)

$x+408$ pages, $\$ 95.00$

ISBN 90-5699-224-4

The importance of texture to materials properties cannot be overstated. The vast majority of properties are anisotropic, and the understanding and exploitation of this anisotropy can yield great dividends in terms of materials performance. Recent renewed interest in texture analysis has been stimulated by a major development in materials research-electron backscatter diffraction (EBSD) and orientation imaging/mapping. The ability to measure crystallographic orientations in the scanning electron microscope (SEM) at predetermined positions on a specimen surface at a rate that currently exceeds 10 measurements per second (and that will only get faster!) has provided materials researchers with a tool that 20 years ago could only have been dreamed of. By this development, the role of the SEM has been dramatically expanded to the point where it is truly a complementary instrument to the transmission electron microscope (TEM) with imaging, diffraction, and phase-analysis capabilities.

Valerie Randle and Olaf Engler have written a book that links the microtexture measurement techniques with more traditional macrotexture techniques that use $x$-ray and neutron diffraction. Their approach is in part historical, which, for those of us who lived through some of this history, is very enjoyable. The early chapters deal with the various methods for describing orientations and misorientations, and also give some background diffraction theory. The next section provides an overview of the measurement, evaluation, and representation of macrotexture. However, the main strength of this book lies in the lengthy discussion of microtexture measurement methods. Appropriately, EBSD is covered in the 
greatest depth. Some other micro techniques (e.g., TEM, etch pit analysis, and highly collimated synchrotron radiation techniques) are also covered, but in considerably less depth. One technique that receives very little attention is stereological texture analysis, which has recently been applied to materials textured by templated grain growth. Phase identification by EBSD is briefly discussed; this is an area where significant progress is expected in the next few years.

The authors illustrate their topics with a number of excellent examples, many drawn from their own work. The 12 case studies at the end of the book provide further insights into the capabilities of the various techniques; the authors stress the need to use complementary techniques. I have one minor gripe: The authors' choice of examples and case studies is heavily biased toward bulk metals. It would have been instructive to see a greater variety of materials and more thin-film case studies. The bias in the early days of the EBSD technique toward the analysis of cubic metals arose in part because it is easier to obtain diffraction patterns from good conductors. As the authors state, poor conductors must be coated to obtain useable diffraction patterns; some discussion of the details of the coating (such as material and thickness) would have been welcome.

This is definitely a book for the practitioner who is looking for information on experimental aspects of the techniques of microtexture. It opens with a very good glossary and closes with six useful appendices. While not a textbook, it is currently by far the best available general source of information in this field. In particular, Chapters 6 and 7 provide a rich seam of experimental detail that is not available anywhere else. The field is still changing fast, but after 20 years of rapid development, the technique has matured to the point where it is considered by many materials scientists to be a standard analysis tool. Various aspects of the technique appear to have stabilized, and a number of excellent systems for data collection and analysis are now on the market. This book has appeared at an appropriate time, and one welcome benefit of its publication may be that the field adopts a single acronym for the technique-EBSD_-instead of the jungle of competing acronyms that has grown up over the decades.

Reviewer: Mark Vaudin is in the Ceramics Division of the National Institute of Standards and Technology. He works on texture measurement techniques and standards, and on texture investigations in bulk and thin-film ceramics and metals.

\section{Handbook of Ceramics Grinding and Polishing}

Ioan Marinescu, Hans K. Tonshoff, and Ichiro Inasaki, Editors

(Noyes Publications, William Andrew

Publishing, Norwich, New York, 2000)

$x x i+450$ pages, $\$ 145.00$

ISBN 0-8155-1424-7

Perhaps the greatest impediments to the commercialization of structural ceramics are the difficulties experienced in grinding these hard materials, (e.g., between $10 \mathrm{GPa}$ and $25 \mathrm{GPa}$ ). A handbook of grinding should be welcomed by researchers and industrial practitioners in this emergent field.

Ceramics are important engineering materials, partly due to their high potential strength and hardness. A vast number of compounds of oxides-carbides and nitrides, for example — can be synthesized as polycrystals or even as single crystals. However, in the manufacture of these varied materials, they are commonly ground to a required shape and precise dimensions for engineering applications.

The fundamental problem with machining advanced ceramics is that the cost of this process is frequently half the total cost of the product. Increasing the rate of stock removal usually increases the subsurface damage and the strength can be dramatically impaired. Unfortunately, ductile grinding, as opposed to brittle-mode grinding, is not the answer because it is simply not economical for most components.

The handbook under review consists of chapters on the properties of ceramics, deformation and fracture of ceramic materials, abrasive processes, grinding, honing and superfinishing, lapping, and polishing. The three editors have research groups in the United States, Germany, and Japan, respectively. One might have expected that they would bring the reader to the state of the art in this field, but they fall short.

It is unclear to whom this handbook is addressed. Is it the general engineer, the industrial specialist, or the university or government laboratory researcher? The multi-authors may have had different goals. The first chapter, which reviews the properties of ceramic materials, could be considered an introduction for engineers unfamiliar with these materials. It is indeed a starting point, but only nine references are given, with no books on ceramics, which would be a good starting place for the beginner. Tables, graphs, and even equations are presented without any references.

The second chapter, on deformation and fracture, is only 26 pages long, yet two full pages are given to the well-known picture of an edge and a screw dislocation. The chapter on abrasive processes has the opportunity to draw from an extensive scientific literature, but many of the topics are only briefly treated, neither satisfying the neophyte looking for an introduction to the subject nor the researcher seeking a critical review.

The longest chapter of the book, on grinding, has seven authors. Some sections, like the ones on dressing and truing and on grinding machines, are informative; however, the referencing is utterly inconsistent, and some authors give no references at all.

Finally, the appendix on case studies should appeal to the hands-on machinist, but regrettably no grinding specificationssuch as depth of cut or in-feed ratemachining times, or costs are mentioned. This is surprising given that the book jacket states "the greatest challenge to increasing the use of ceramic parts is reducing the cost of machining operations."

To conclude, I was hoping that this handbook would be helpful to those working, mainly empirically, in this branch of technology. In companies, machinists rarely read the literature and each job is frequently a beginning and an end. The hierarchy is production first, know-how second, and understanding a distant third. This approach to engineering does have its limitations, and there is a spillover into academia and national laboratories. To climb the true learning curve of understanding (and ultimately control) requires carefully designed experiments, precise measurements, an understanding of the material being machined, the mechanism of material removal, and modeling. The materials science approach is sorely needed here.

When it comes to books and reviews, there is, in my opinion, an urgent need to address complex fields such as tribology, in which there are numerous publications but little synthesis of the different studies. A talented specialist is required to critically review this literature, make sense of it, and make generalizations. Coincidentally, a magnificent Handbook of Ceramic Hard Materials, edited by Ralf Riedel, has recently been published by John Wiley \& Sons (2000). This book illustrates the difference between science and engineering.

Reviewer: Ted Lilley was until recently a senior scientist at St. Gobain/Norton Company, where he developed high-performance ceramics, which included machining and polishing. Last year he was a visiting professor at the University of Witwatersrand, South Africa, establishing a ceramics processing program. 


\section{The Binns Medalists}

\section{Margaret L. Carney}

(Schein-Joseph International Museum

of Art, Alfred, NY, 2000)

133 pages, $\$ 30.00$

Rarely do the book-review pages of MRS Bulletin include catalogues from art exhibitions. The Binns Medalists, however, is a special volume. Charles Fergus Binns has been popularly referred to as the "father of American studio ceramics," and the Binns Medal named in his honor has been awarded to individuals for excellence in ceramic art. This catalogue was produced on the occasion of the exhibition "The Binns Medalists" at the Centennial of the New York State College of Ceramics (1900-2000).

Binns' connection with ceramics is twofold. He was the founding director of the New York State School of ClayWorking and Ceramics (now the New York State College of Ceramics at Alfred
University) in 1900 . He was also a cofounder of the American Ceramic Society (ACerS). Believing in a balance between art and science, he was both a ceramic artist and a ceramic scientist. He experimented with clay sources and glaze formulae, and he wrote prolifically to make his information accessible. With his connections to the American Ceramic Society, it may not be surprising that the Binns Medals enjoyed greatest success when awarded during the annual ACerS meetings. The award committee originally consisted of five members, with Binns serving as the first chair. At the time of the exhibition, 35 Binns Medals had been awarded between 1929 and 1998, with some small gaps and one large (1962-1993) gap.

The catalogue makes a very enjoyable read. M.L. Carney first describes the Binns Medal in the context of American medallic art and then offers a history of the medal. Not always available in an art catalogue, an entire page is devoted to a (highly selective) biography of each of the medalists. Finally, wonderful photographic reproductions of the works of the medallists are presented. In a catalogue covering threequarters of the 20th century, one might expect to see an evolutionary aspect to these pages, but the artists, the media, and the temperaments are so broad that one can only wonder at the array of ceramic art. This is indeed a lovely volume.

Reviewer: Gabrielle Long is Leader of the Materials Microstructural Characterization Group in the Ceramics Division of the Materials Science and Engineering Laboratory at the National Institute of Standards and Technology. Her research interests include metal and ceramic deformation, small-angle scattering and $x$-ray optics, $x$-ray inelastic scattering, anomalous scattering, and dynamical diffraction by imperfect (real) crystals. Long serves on the MRS Bulletin Book Review Board. 